\title{
Prevalence of hypertension, arterial stiffness and risk factor association
}

\begin{abstract}
Background: Cardiovascular diseases are the main cause of mortality worldwide and are directly linked to their risk factors, highlighting systemic arterial hypertension (SAH). Pulse wave velocity (PWV) is a predictor of cardiovascular risk. Its increase directly implies morbidity and mortality.

Objective: To estimate the prevalence of SAH and arterial stiffness in a community in Salvador-BA to stratify and verify association according to sociodemographic and clinical characteristics.

Method: Cross-sectional study in the Vale do Ogunjá, Salvador-BA. Sociodemographic variables were analyzed using a questionnaire survey. The examinations were performed at the FTC Clinic, such as the measurement of arterial stiffness using the SphygmoCor applanation tonometer (Atcor Medical Blood Pressure Analysis System, Sydney, Australia). Prevalence was used as a measure of occurrence, Prevalence Ratio (PR) and several confidence intervals $(95 \% \mathrm{CI})$ as a measure of association, estimated as a function of Odds Ratio using binary logistic regression. The $5 \%$ level of statistical significance was adopted.

Results: 151 individuals were studied, the prevalence of SAH was $30.46 \%$ and Arterial Stiffness was $25.2 \%$. There was an association between these variables and the chance of having arterial stifness in the presence of SAH is 3.7 times greater in relation to nonhypertensive patients, PR $3.7(p<0.05 ; 95 \%$ CI: $1.6-8,5)$. SAH was associated with age, dysglycemia and overweight, while arterial stiffness was associated with age between 40 to 74years, low education and obesity.

Conclusion: There was a prevalence of SAH $30.7 \%$ and arterial stiffness $25.8 \%$, and an association of exposure with age and BMI was also observed.
\end{abstract}

Keywords: hypertension, arterial stiffness, epidemiology, prevalence, pulse wave analysis
Volume I 3 Issue 6 - 2020

\author{
Antonio de Assis Oliveira Alves Filho,' Rafael \\ Oliveira Lopes, ${ }^{2}$ Roberta de Castro Araújo \\ Cunha, ${ }^{2}$ Juan Jailson Oliveira Almeida Costa, ${ }^{2}$ \\ Larissa Ribeiro Bessa, ${ }^{2}$ Rodrigo Lins Sant'Ana \\ de Lima, ${ }^{2}$ Alana dos Reis Silva, ${ }^{2}$ Magno \\ Conceição das Merçês, ${ }^{2}$ Diorlene Oliveira \\ da Silva, ${ }^{2}$ Cecília Freitas da Silva Araújo,' \\ Nivaldo Menezes Filgueiras Filho, ${ }^{2}$ Lucélia \\ Batista Neves Cunha Magalhães \\ 'Department of Cardiology, Salvador University, Brazil \\ ${ }^{2}$ Department of Cardiology, University of Technology and \\ Science, Brazil
}

Correspondence: Antonio Alves Filho, UniFTC - University of Technology and Science, Salvador, Bahia, Brasil, Tel+5571992523971, Email antonioassisofilho@gmail.com

Received: November 25, 2020 | Published: December 31, 2020

\section{Introduction}

Arterial hypertension (AH) is the most common disease in adulthood. In Brazil, the estimated prevalence of SAH in 2018 was $24.7 \%$ in adults and above $60.9 \%$ in the elderly population. ${ }^{1}$ Frequently associated with metabolic disorders, functional or structural changes in target organs, and aggravated by the presence of other risk factors (RF), such as dyslipidemia, abdominal obesity, glucose intolerance and diabetes mellitus (DM). ${ }^{2,3}$ Although SAH is directly related to age, some factors predispose the disease at an early stage, such as obesity., ${ }^{3}$ $\mathrm{DM}^{4}$ and physical inactivity, ${ }^{5}$ which are directly linked to oxidative tissue stress and chronic inflammation. In addition, it causes a high social cost and is the main risk factor for cardiovascular mortality.

Vascular stiffening is characterized as an important cardiovascular risk factor and other comorbidities. ${ }^{6}$ The arterial stiffness is a complex phenomenon that occurs due to decreased complacency of the large vessels, generally associated with aging and other conditions, such as diabetes mellitus, atherosclerosis, obesity ${ }^{4}$ and chronic kidney disease (CKD). ${ }^{7}$
The use of the Carotid to Femoral Pulse Wave Velocity (cf-PWV) by the Sphygmocor device is generally considered the reference standard (gold) for assessing arterial stiffness, ${ }^{6,8}$ with greater precision, and being a non-invasive method. Arterial stiffening is influenced by hemodynamic forces and extrinsic factors such as hormones ${ }^{4,7}$ and inflammatory meters, ${ }^{9}$ which may be related to glucose and sodium intake. Currently, PWV is a strong predictor of cardiovascular risk and all causes of mortality, in addition to an increase in mortality of $14 \%$ in differences of $1 \mathrm{~m} / \mathrm{s}$ in its measurement. ${ }^{10}$

Arterial stiffness has been increasingly used as a predictor of cardiovascular risk, showing great impact in relation to mortality ${ }^{11}$ in addition to being considered a target organ injury when it is out of normal. ${ }^{6}$ PWV emerged as the gold standard method due to its relative ease of measurement, its accuracy and the large number of evidence demonstrating its association with the incidence of cardiovascular diseases (CVD), regardless of the risk factors of the studied populations. ${ }^{4,5,11,12}$

Due to the clinical importance of SAH and arterial stiffness, in addition to the high cost generated to public health, the present 
study aims to estimate the prevalence of these clinical conditions in a distinguished clinic in Salvador/BA, besides stratifying according to sociodemographic and clinical characteristics and to verify associations between exposures with the characteristics set out above.

\section{Materials and methods}

This work is executed in a large study called Project VASCOR, which aims to investigate an association between metabolic syndrome, chronic low-intensity inflammatory state and arterial stiffness in the community located in the Vale do Ogunjá, in Salvador, Bahia.

\section{Study design and type}

Cross-sectional, observational, analytical, population-based study in the Vale do Ogunjá, located in the Acupe de Brotas neighborhood, Salvador, Bahia. The cut of this study corresponds to the data collected from the period from Dec/2016 to May/2019.

Population: The target population of the study consists of individuals living in the neighborhood of Vale do Ogunjá, Acupe de Brotas, both genders, aged over 18years. Bedridden, pregnant women, employees of the FTC clinic and refusals during the period from December 2016 to May 2019 were excluded. A simple random sample of 301 individuals was estimated, a sampling error of $4.5 \%$ was considered, a sampling error of $5 \%$, including $25 \%$ of losses, from an area divided into 12 census sectors. According to data from the IBGE Census (2010), the region has 7,450 adult residents.

\section{Instruments for data production}

Forms were filled out from an interview with the patients, with objective and descriptive questions regarding the sociodemographic and clinical characteristics of the patients. Blood pressure measurements are made at the FTC Clinic, using the Omron 110 HPB device, calibrated with "adult standard" and "large adult" cuffs. ${ }^{13,14}$ Three measurements were taken on the patient's left arm, in supine position, with rest of at least 5 minutes and with intervals of 1 minute between measurements, the use of caffeine, cigarettes was ruled out and the patient was not bladder filled. The measurement used for blood pressure is the average between the last two measurements, approximating the number above the non-integer number.

Anthropometric measurements, weight and height, will be performed with an anthropometric standard calibration scale certified by INMETRO.${ }^{15}$ Weight will be determined in kilograms and height in meters, using a scale stadiometer. The material for complementary blood tests will be collected in the same unit, fasting for 12 hours or more. The biochemical analyzes of fasting blood glucose and lipid profile (total cholesterol, fractions and triglycerides), were performed by the automated method, using immunochemistry and immunoassay techniques (A25 system, BIOSYSTEMS SA, Barcelona, Spain).

\section{Pulse wave speed}

The carotid-femoral pulse wave velocity was measured noninvasively using the SphygmoCor applanation tonometer (Atcor Medical Blood Pressure Analysis System, Sydney Australia). The methodology used by SphygmoCor is to assess the peak of the $\mathrm{R}$ wave, associated with the beginning of the pulse wave and its morphological evaluation. ${ }^{16,17}$ The PWV measurement is generally accepted as the simplest, most robust, and reproducible method for determining arterial stiffness. The carotid and femoral pulse waves are measured right after the QRS complex of the EKG and the time taken to get from the carotid to the femoral is calculated. That is, the peak of the $\mathrm{R}$ wave until the beginning of the pulse wave, in consecutive waves automatically calculated by the SphygmoCor. The femoral carotid length was measured in millimeters with an inelastic tape and the final value was corrected by the constant 0.80 . Only measures with standard deviation were used, in the case of PWV, less than or equal to $10 \% .^{18}$

\section{Description of variables and abnormality criteria}

\section{Dependent variables}

Hypertensive individuals were added according to self-reported use of antihypertensive medications or prior diagnosis or have presented systolic pressure $\geq 180 \mathrm{mmHg}$ or diastolic pressure $\geq$ $110 \mathrm{mmHg}{ }^{2}$ Arterial stiffness was classified with corrected cf-PWV values $\geq 10 \mathrm{~m} / \mathrm{s}^{18}$

\section{Independent variables}

The age group defined in years and categorized by age groups in 3 groups: $<40$ years old, 40 and 75 years old and $>75$ years oldand more. Gender was defined as male and female, according to current documentation. The race/color was self-defined by the individuals by their skin color in white, black/mulatto, brown/mulatto and others defined by the Brazilian demographic censuses. Marital status was defined as single, married/civil union, divorced. Schooling was defined as low, representing incomplete or complete elementary school and illiterate (up to the 5th year of 1st grade). Defined as médium, representing incomplete or complete high school, between 6th year of 1 st grade and 3rd year of 2nd grade. And high in incomplete or complete higher education. Family income was defined as the number of minimum wages in the family environment. Dyslipidemia was defined by total cholesterol $>190 \mathrm{mg} / \mathrm{dL}$, HDL $<40 \mathrm{mg} / \mathrm{dL}$ or LDL $>130 \mathrm{mg} / \mathrm{dL}$. Smoking by current smoker, regardless of smoking burden. The body mass index (BMI) was calculated according to the quetelet index, calculated as follows: weight $/$ height $^{2}$ and the current weight classification using the Quetelet index, World Health Organization (WHO), defined as Eutrophic $<25 \mathrm{~kg} / \mathrm{m}^{2}$, overweight $\geq 25 \mathrm{~kg} / \mathrm{m}^{2}$ and $<30 \mathrm{~kg} / \mathrm{m}^{2}$ and obesity $\geq 30 \mathrm{~kg} / \mathrm{m}^{2}$. Dysglycemia was characterized by a previous diagnosis of DM, use of current treatment or fasting blood glucose $>100 \mathrm{mg} / \mathrm{dL}$. Abdominal/central obesity was considered with values in females $>80 \mathrm{~cm}$ and in males $>94 \mathrm{~cm}$.

\section{Data analysis}

The data were entered into a GoogleDocs form after typing, exported to the STATA v.12 statistical software. The initial data analysis consisted of the descrip

tion of the sociodemographic and clinical profile of the study population stratified in two previously defined outcomes SAH and arterial stiffness. The first outcome, Systemic Arterial Hypertension, consisted of two groups of patients with and without hypertension and the second outcome, Arterial Stiffness consisted of two groups with an increased chance of cardiovascular events when $P W V \geq 10 \mathrm{~m} / \mathrm{s}$ and the second, smaller group with risk of cardiovascular events $\mathrm{PWV}<10 \mathrm{~m} / \mathrm{s}$, excluding patients with index_PWV $>10$. 
After, in order to assess the chance of occurrence and the magnitude of the association of SAH and arterial stiffness in the study population, measures of occurrence and association of the increased chance for cardiovascular events were obtained according to sociodemographic and clinical characteristics

Descriptive and dispersion measures (mean and standard deviation) and univariate and bivariate frequency distributions were used. To verify proportional differences between the groups, Pearson's Chisquare and Fisher's Exact tests (frequencies $<5$ ) were used for the nominal categorical variables and the Chi-square Trend test for the ordinal categorical variables.

Prevalence was used as a measure of occurrence and the Prevalence Ratio (PR) and respective confidence intervals (95\%CI) as an association measure, estimated according to Odds Ratio (OR) using binary logistic regression. The $5 \%$ level of statistical significance was adopted.

\section{Ethical aspects}

The project follows the Declaration of Helsinki (Helsinki VII), being submitted to the CEP of the UniFTC which approved it through protocol $\mathrm{N}^{\circ} 1827621$ according to the ethical precepts of Resolution $466 / 2012$ of the National Health Council. Before the interview, the entire research process was explained. The informed consent form was read and signed. All care with the security and confidentiality of information was ensured. Each participant is given the results of the exams, a brief report and priority to follow-up at the Integrated Teaching and Health Center (Clínica FTC do Ogunjá). All participants signed a Free and Informed Consent Form.

\section{Results}

151 individuals were evaluated. The global sample was constituted predominantly by the female gender, the average age was 48.2 $( \pm 16.9)$ years, predominant age group between 40 and 74years old and medium schooling level. One of the individuals evaluated did not report their race/color, marital status, smoking habits, as well as their level of education. Therefore, these variables were only evaluated in 150 individuals.

Regarding the sample population, there is a predominance of selfdeclared blacks/browns, single and non-smokers. Family income was reported by 144 patients, with a predominance of 1 to 3 minimum wages (Table 1). Laboratory tests were carried out on 148 individuals, showing a predominance of normoglycemic and non-dyslipidemic individuals. LDL values showed an average of $125.6 \mathrm{mg} / \mathrm{dL}( \pm 39.2)$, HDL of $53.6 \mathrm{mg} / \mathrm{dL}( \pm 15.3)$, fasting blood glucose of $102.6 \mathrm{mg} /$ $\mathrm{dL}( \pm 30.6)$. Anthropometric measurements were performed on 147 individuals, indicating a predominance of eutrophic individuals (Table 1).

Blood pressure was measured in all individuals and the sample was stratified into 2 groups (hypertensive and non-hypertensive). There was a predominance of normotensive individuals, $69.54 \%$, and SAH was observed in $30.46 \%$ of the individuals evaluated. There were statistically significant proportional differences between normotensive and hypertensive patients, for the variables age group, BMI, waist circumference and capillary blood glucose $(p<0.05)$.
The groups were homogeneous in relation to sociodemographic characteristics, dyslipidemia and smoking $(\mathrm{p}>0.05)$ (Table 1). Among hypertensive individuals the average age was $56.1( \pm 16.6)$ years, while in non-hypertensive individuals it was $44.7( \pm 15.9)$ years. In view of hypertensive patients, there was a higher frequency of females, aged 40 to 74years old, self-reported color black/brown, single marital status, medium education level, family income of 1 to 3 minimum wages, BMI obesity, fasting glucose $<100 \mathrm{mg} / \mathrm{dL}$, non-dyslipidemic and non-smokers $(93.5 \%)$ (Table 1).

Among hypertensive individuals the average age was $56.1( \pm 16.6)$ years, while in non-hypertensive individuals it was $44.7( \pm 15.9)$ years. In view of hypertensive patients, there was a higher frequency of females, aged 40 to 74 years old, self-reported color black/brown, single marital status, medium education level, family income of 1 to 3 minimum wages, BMI considering obesity, fasting blood glucose $<100 \mathrm{mg} / \mathrm{dL}$, non-dyslipidemic and non-smokers (93.5\%) (Table 1).

PWV was measured in all individuals in the study, however 20 individuals had unsatisfactory quality of the exam, totaling a sample of 131 individuals. Among all patients, $74.8 \%$ had PWV within normal values $(<10 \mathrm{~m} / \mathrm{s})$, however $25.2 \%$ had increased values $( \pm 10 \mathrm{~m} / \mathrm{s})$. Analyzing individuals with arterial stiffness and without arterial stiffness, the age group, BMI and SAH variables showed statistically significant proportional differences $(\mathrm{p}<0.05)$ (Table 2$)$.

Considering the group of patients with arterial stiffness, there was a predominance of females, aged between 40 and 74years old, self-reported color black/brown, marital status married /civil union, medium education level, family income of 1 to 3 minimum wages , overweight BMI, capillary glycemia $<100 \mathrm{mg} / \mathrm{dL}$, non-smokers, normotensive and abdominal circumference within the normal range (Table 2).

When analyzing the magnitude of the associations identified, by estimating the prevalence ratio (PR), as an outcome for arterial stiffness, it was observed that older age group were more likely to develop arterial stiffness; especially the population between 40 and 74 years old who presented 7.5 times more chance compared to those aged <40years old (95\% CI: 2.4-23.1). Patients who had less education had a higher chance compared to those with higher level, being 3.5 (95\% CI: 1.1-11.7). Analyzing the BMI, obese individuals were 2.9 times more likely to develop arterial stiffness compared to eutrophic individuals (95\% CI: 1.0-7.6), this result is not statistically significant. Hypertensive patients are 3.7 times more likely to have arterial stiffness compared to normotensive patients (95\% CI: 1.6-8.5). Other associations with arterial stiffness did not show a statistically significant risk (Table 3).

When analyzing the identified associations with $\mathrm{SAH}$ as an outcome, it was observed that there was a greater chance of having SAH in older groups compared to those younger than 40 years old; 40-74 years old had 2.7 more chances (95\% CI: 1.2-6.2) and $\geq$ 75 years old had 4.7 more chance (95\% CI: 1.1-19.3), when compared with $<40$ years. Overweight individuals also had 3.3 more chances (95\% CI: 1.3 to 8.3 ); obese individuals were 1.7 times more likely to have SAH (95\% CI: 0.7-4.2) when compared to normal weight individuals. Patients considered dysglycemic were also found to have a greater chance of SAH, being 2.4 (95\% CI: 1.2-4.9) when compared to normal patients (Table 3). 
Table I Proportional distribution of Systemic Arterial Hypertension (SAH) according to sociodemographic and clinical characteristics of patients seen at the Integrated Health Center $(\mathrm{n}=15 \mathrm{I})$. Salvador-Bahia, 2019

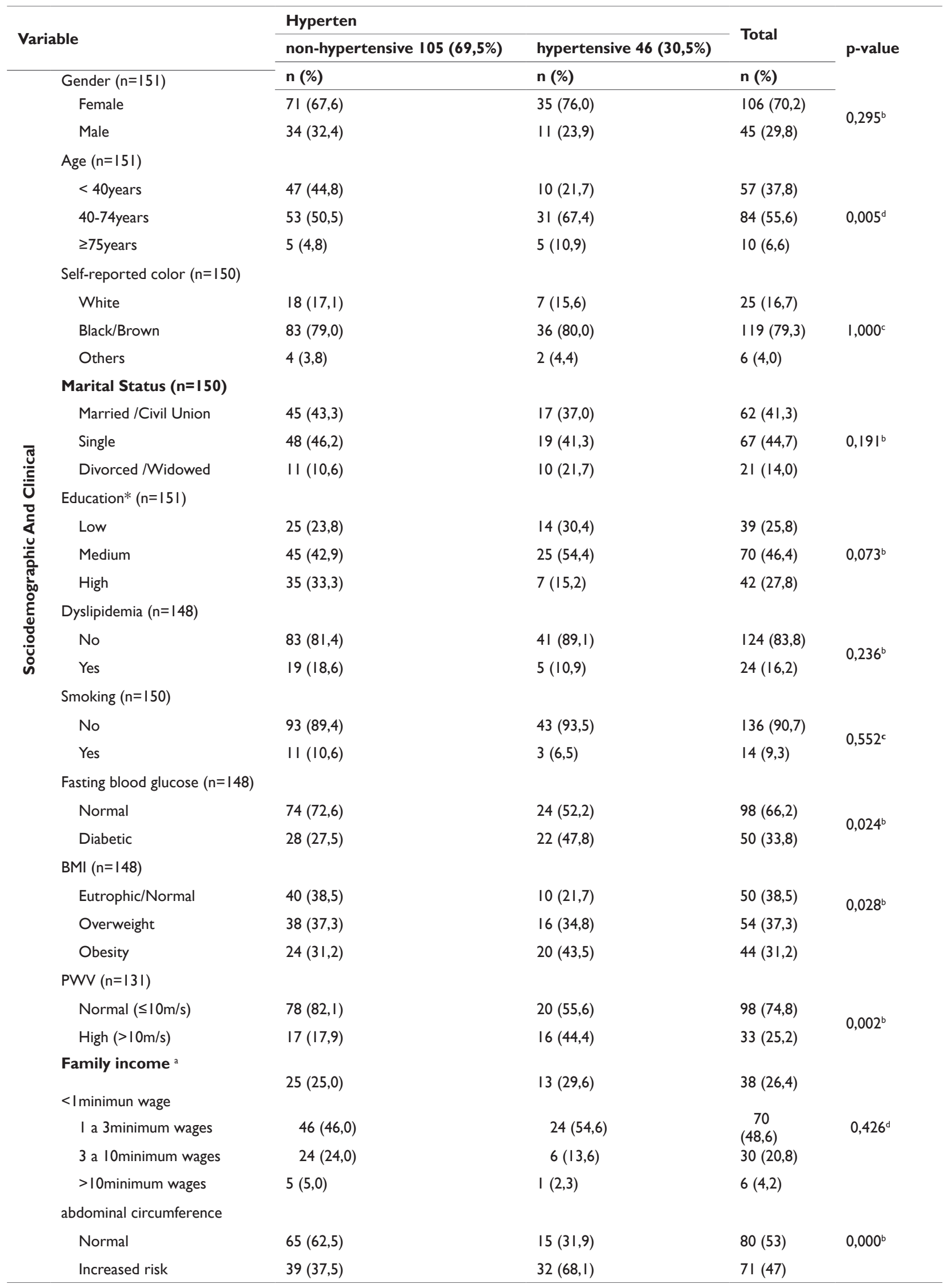

Note: Minimum wage $\mathrm{R} \$$ 954.00; mean age $( \pm \mathrm{sd})=49.4$ ( \pm | 4.2) years; b Pearson’s Chi-square test; c Fischer's exact test; $d$ Chi-square Trend Test; *Complete and incomplete education levels were aggregated into the same category

Citation: Filho AAOA, Lopes RO, Cunha RCA, et al. Prevalence of hypertension, arterial stiffness and risk factor association.J Cardiol Curr Res. 2020; I3(6): I67-I74. DOI: I0.15406/jccr.2020.13.00497 
Table 2 Proportional distribution of arterial stiffness according to sociodemographic and clinical characteristics of patients seen at the Integrated Health Center (Centro Integrado de Saúde ) $(n=131)$. Salvador-Bahia, 2019

\begin{tabular}{|c|c|c|c|c|c|}
\hline \multirow{3}{*}{ Variables } & & \multicolumn{2}{|c|}{ Adjusted PWV (m/s) } & \multirow{2}{*}{ Total } & \multirow{3}{*}{ p-value } \\
\hline & & \multirow{2}{*}{$\begin{array}{l}\text { Normal (74,8\%) } \\
\text { n (\%) }\end{array}$} & \multirow{2}{*}{$\begin{array}{l}\text { Arteria Stiffness }(25,8 \%) \\
\text { n (\%) }\end{array}$} & & \\
\hline & & & & n (\%) & \\
\hline \multirow{35}{*}{ 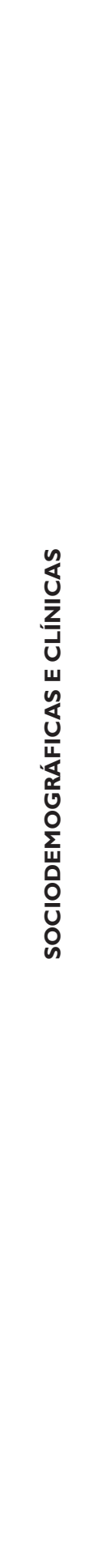 } & Gender $(n=|3|)$ & & & & \multirow{3}{*}{$0,297^{a}$} \\
\hline & Female & $69(70,4)$ & $20(60,6)$ & $89(67,9)$ & \\
\hline & Male & $29(29,6)$ & $13(39,4)$ & $42(32,0)$ & \\
\hline & Age $(n=\mid 11)$ & & & & \\
\hline & $<40$ years old & $49(50,0)$ & $4(12,1)$ & $53(40,5)$ & \multirow{3}{*}{$0,00 I^{a}$} \\
\hline & 40 a 74 years old & $44(44,9)$ & $27(81,8)$ & $7 \mid(54,2)$ & \\
\hline & $\geq 75$ years old & $5(5, I)$ & $2(6,1)$ & $7(44,1)$ & \\
\hline & Self-reported color $(n=$ & & & & \\
\hline & White & $16(16,5)$ & $6(18,2)$ & $22(16,9)$ & \multirow{3}{*}{$\mathrm{I}, 000^{\mathrm{b}}$} \\
\hline & Black/Brown & $76(78,4)$ & $26(78,8)$ & $102(78,5)$ & \\
\hline & Others & $5(5, I)$ & I $(3,0)$ & $6(4,6)$ & \\
\hline & Marital Status $(n=130)$ & & & & \\
\hline & Married/ Civil union & $42(42,9)$ & $15(46,9)$ & $57(43,8)$ & \multirow{4}{*}{$0,553^{a}$} \\
\hline & Single & $46(46,9)$ & $12(37,5)$ & $58(44,6)$ & \\
\hline & Divorced/Widowed & $10(10,2)$ & $5(15,6)$ & $15(1 \mathrm{I}, 5)$ & \\
\hline & Education* $(n=|3|)$ & & & & \\
\hline & Low & $2 I(2 I, 4)$ & II $(33,3)$ & $32(24,4)$ & \multirow{3}{*}{$0,086^{a}$} \\
\hline & Medium & $43(43,9)$ & $\mid 7(5 \mid, 5)$ & $60(45,8)$ & \\
\hline & High & $34(34,7)$ & $5(15,2)$ & $39(29,8)$ & \\
\hline & Dyslipidemia $(n=\mid 28)$ & & & & \\
\hline & No & $81(85,3)$ & $26(79,8)$ & $107(83,6)$ & \multirow{2}{*}{$0,387^{a}$} \\
\hline & Yes & $14(14,7)$ & $7(2 \mid, 2)$ & $21(16,4)$ & \\
\hline & Smoking $(n=130)$ & & & & \multirow{3}{*}{$\mathrm{I}, 000^{\mathrm{b}}$} \\
\hline & No & $87(89,7)$ & $30(90,9)$ & $117(90,0)$ & \\
\hline & Yes & $10(10,3)$ & $3(9,0)$ & $13(10,0)$ & \\
\hline & \multicolumn{4}{|c|}{ Fasting blood glucose $(n=\mid 28)$} & \multirow{4}{*}{$0,199^{b}$} \\
\hline & Normal & $67(70,5)$ & $19(57,6)$ & $86(67, I)$ & \\
\hline & Diabetic & $28(29,5)$ & $14(42,4)$ & $42(32,8)$ & \\
\hline & BMI $(n=127)$ & & & & \\
\hline & Eutrophic / Normal & $37(38,5)$ & $8(25,8)$ & $45(35,4)$ & \multirow{3}{*}{$0,010^{b}$} \\
\hline & Overweight & $30(31,3)$ & $19(61,3)$ & $49(38,6)$ & \\
\hline & Obesity & $29(31,2)$ & $4(12,9)$ & $33(26,0)$ & \\
\hline & \multicolumn{4}{|c|}{ Arterial hypertension $(n=|3|)$} & \\
\hline & Non-hypertensive & $78(79,6)$ & $\mid 7(5 \mid, 5)$ & $95(72,5)$ & \multirow{2}{*}{$0,002^{b}$} \\
\hline & Hypertensive & $20(20,4)$ & $16(48,5)$ & $36(27,5)$ & \\
\hline
\end{tabular}


Table Continued..

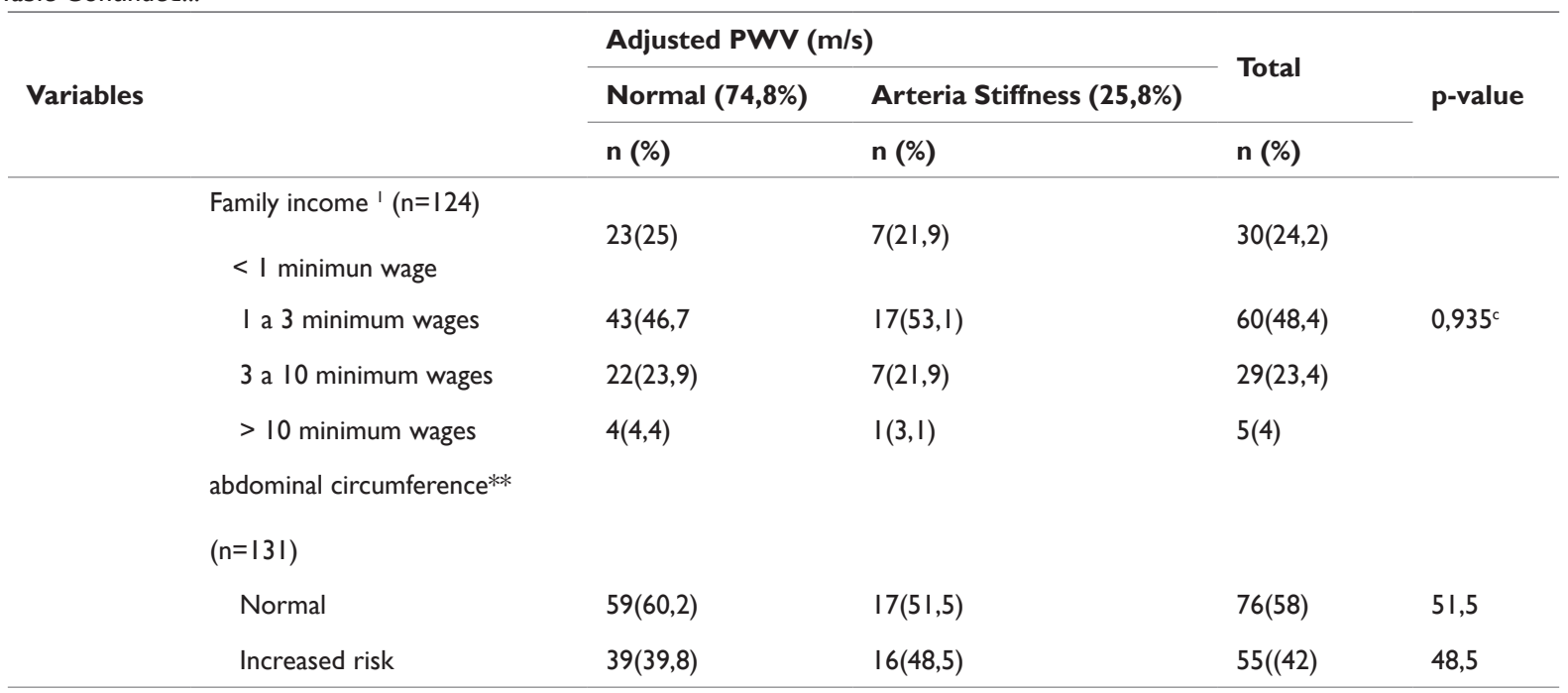

Table 3 Prevalence and Prevalence Ratio of cardiovascular risk factors $(n=15 I)$. Salvador BA. Collection period from Jan/2016 to May/20I9

\begin{tabular}{|c|c|c|c|c|}
\hline \multirow{2}{*}{ Variables } & \multicolumn{2}{|c|}{ Arterial Stiffness $(n=|3|)$} & \multicolumn{2}{|c|}{ Systemic arterial hypertension $(n=|5|)$} \\
\hline & Prevalence(\%) & PR (Cl95\%) & Prevalence (\%) & $\mathbf{P R}^{\mathrm{a}}(\mathbf{C l 9 5 \% )}$ \\
\hline \multicolumn{5}{|l|}{ Gender } \\
\hline Male & 22,5 & 1 & 33 & 1 \\
\hline Female & 31,0 & $1,5(0,7-3,5)$ & 24 & $0,7(0,3-1,4)$ \\
\hline \multicolumn{5}{|l|}{ Age* } \\
\hline$<40$ years old & 8 & 1 & 18 & I \\
\hline 40 - 74years old & 38 & $7,5(2,4-23,1)$ & 37 & $2,7(1,2-6,2)$ \\
\hline$\geq 75$ years old & 29 & $4,9(0,7-3,7)$ & 50 & $4,7(I, I-19,3)$ \\
\hline \multicolumn{5}{|l|}{ Self-reported color } \\
\hline White & 27 & 1 & 28 & I \\
\hline Black/ Brown & 25 & $0,9(0,3-2,6)$ & 30 & $\mathrm{I}, \mathrm{I}(0,4-2,9)$ \\
\hline Others & 17 & $0,5(0, I-5,5)$ & 33 & $1,2(0,2-8,6)$ \\
\hline \multicolumn{5}{|l|}{ Marital Status } \\
\hline Married/ Civil union & 21 & $0,7(0,3-1,7)$ & 28 & $1,0(0,5-2,3)$ \\
\hline Single & 26 & I & 27 & 1 \\
\hline Divorced / Widowed & 33 & I,4 (0,4-4,8) & 48 & $2,4(0,9-6,7)$ \\
\hline \multicolumn{5}{|l|}{ Education* } \\
\hline Low & 34 & $3,5(I, I-\mid I, 7)$ & 36 & $2,8(1,0-7,9)$ \\
\hline Medium & 28 & $2,6(0,9-8,0)$ & 36 & $2,7(1,0-7,2)$ \\
\hline High & 13 & 1 & 17 & I \\
\hline \multicolumn{5}{|l|}{ Dyslipidemia } \\
\hline No & 24 & 1 & 33 & I \\
\hline Yes & 33 & I,6 $(0,6-4,3)$ & 21 & $0,5(0,2-1,5)$ \\
\hline \multicolumn{5}{|l|}{ Smoking } \\
\hline No & 26 & 1 & 32 & I \\
\hline Yes & 23 & $0,87(0,2-3,3)$ & 21 & $0,6(0,2-2,2)$ \\
\hline
\end{tabular}




\begin{tabular}{|c|c|c|c|c|}
\hline \multirow{2}{*}{ Variables } & \multicolumn{2}{|c|}{ Arterial Stiffness $(n=|3|)$} & \multicolumn{2}{|c|}{ Systemic arterial hypertension $(n=|5|)$} \\
\hline & Prevalence(\%) & PR (Cl95\%) & Prevalence (\%) & $\mathbf{P R}^{\mathrm{a}}(\mathrm{Cl} 195 \%)$ \\
\hline \multicolumn{5}{|c|}{ Fasting blood glucose } \\
\hline Normal & 22 & 1 & 24 & 1 \\
\hline Diabetic & 33 & $\mathrm{I}, 8(0,8-4,0)$ & 44 & $2,4(1,2-4,9)$ \\
\hline \multicolumn{5}{|l|}{$\mathrm{BMI} *$} \\
\hline Eutrophic & 18 & 1 & 25 & 1 \\
\hline Overweight & 39 & $0,6(0,2-2,3)$ & 29 & $3,3(1,3-8,3)$ \\
\hline Obesity & 12 & $2,9(1,1-7,6)$ & 45 & $\mathrm{I}, 7(0,7-4,2)$ \\
\hline \multicolumn{5}{|l|}{$\mathrm{SAH}^{*}$} \\
\hline No & 18,0 & 1 & 20,4 & \\
\hline Yes & 44,4 & $3,7(1,6-8,5)$ & 48,5 & \\
\hline
\end{tabular}

Note: $*(p<0.05)$; Prevalence Ratio: estimated as a function of Odds Ratio using binary logistic regression

\section{Discussion}

The present study showed a high prevalence of SAH in agreement with others, such as the systematic review of 13 Brazilian articles reported by Passos et al. ${ }^{19}$ and Lessa et al. ${ }^{20}$ through their research conducted in Salvador-BA with 1439 individuals. Analyzing the age groups, an increase in prevalence was found with advancing age, according to the literature. ${ }^{19-22}$

A higher prevalence of SAH in the female population was observed, differently from that presented by Nogueira et al. ${ }^{22}$ who demonstrated SAH equivalence between genders. Although there was a predominance of SAH in females in several other studies. ${ }^{20-23}$

Socioeconomic differences have a direct impact on health care. The lack of access to prevention, and the lack of knowledge about pathologies directly implies an increase in diseases. ${ }^{24}$ In this context, when analyzing the educational level of individuals in the current study, a higher prevalence of SAH was found in low and medium education. Individuals who attended high school had twice the prevalence of SAH compared to individuals with higher education, which was also seen by Lobo et al..$^{21}$ and Piccini et al. ${ }^{25} \mathrm{~A}$ large part of the studied population was self-declared brown/black, but there was no significant difference in prevalence in relation to race/color, an analysis also reported by Cipullo et al. ${ }^{23}$ in their study. However, Lessa et al. ${ }^{20}$ found a higher prevalence of SAH in individuals considered black and brown and they had an increased chance of having SAH.

The assessment of associated risk factors is fundamentally important for SAH prevention and treatment. The identification of risk factors and their control helps in the success of treatment. ${ }^{2}$ In the current study, abdominal obesity and high BMI showed an increased prevalence of SAH compared to normal weight individuals, which was also evidenced by Cipullo et al. ${ }^{23}$ Lessa et al..$^{20}$ In their study is shown that there is an increased chance of being hypertensive in obese individuals in relation to eutrophic individuals, not being observed in the current study, in which only overweight individuals had an increased chance of being hypertensive.

In the current study, a higher prevalence of SAH was observed in patients with arterial stiffness according to the literature, ${ }^{26,27}$ which shows that high blood pressure levels are associated with vascular stiffness. This condition generates an increased cardiovascular risk and it is a predictor of SAH morbidity and mortality. ${ }^{26-30}$ The high prevalence of arterial stiffness was found in the present study, which can be associated with local ethnic and sociodemographic characteristics. ${ }^{26,31,32}$ Cunha et al. ${ }^{26}$ in their study in Portugal, with 2542 individuals observed a prevalence of $18.7 \%$ of arterial stiffness, while in the current study an even higher prevalence was observed. The literature explains the increase in arterial stiffness through physiological changes in the composition of large vessels with age, which is the main factor for the development of arterial stiffness. ${ }^{33,34}$ This result was demonstrated in the study.

Safar et al. ${ }^{27}$ demonstrated, in their study, the association between risk factors such as gender, dyslipidemia and smoking with arterial stiffness in all age groups; in addition, it was demonstrated that in diabetic patients, there was an even greater increase in PWV in relation to the association of the other factors mentioned. In the present study, the risk factors that demonstrated a greater chance of having arterial stiffness were obesity, SAH, low education and advancing age. Muhammad et al. ${ }^{35}$ demonstrated in their cohort with 2450 individuals that the increase in PWV consequently increases the incidence of DM, however, in the current study it did not show an association between high blood glucose levels and arterial stiffness.

The limitations of this study were common to those presented in the cross-sections, with no temporality and causal relationship being observed. The studied sample consists of a preliminary "n" of a representative population-based study. Within the sample studied, some variables suffered losses. The potential of the study was the assessment of arterial stiffness using a non-invasive method as measured by a gold standard device, all individuals came from their own home and the study allows a cohort to be made later.

\section{Conclusion}

The present study demonstrated the prevalence of SAH and arterial stiffness of $30.46 \%$ and $25.9 \%$, respectively. It also showed the relationship of SAH with age, education, abdominal obesity, BMI, capillary glycemia and arterial stiffness. Regarding to arterial stiffness exposure factors, there was only a relationship with age, BMI and $\mathrm{SAH}$. It was concluded that there was a relationship between exposure factors with SAH and arterial stiffness and between them. The study is relevant due to the non-invasive assessment of PWV, an important predictor of cardiovascular risk, contributing to assess the profile of high-risk hypertensive patients. 


\section{Acknowledgments}

None.

\section{Conflicts of interest}

The authors declare there are no conflicts of interest related to the article.

\section{Funding}

None.

\section{References}

1. http://bvsms.saude.gov.br/bvs/publicacoes/vigitel_brasil_2011_fatores risco_doencas_cronicas.pdf

2. http://publicacoes.cardiol.br/2014/diretrizes/2016/05_HIPERTENSAO_ ARTERIAL.pdf

3. Seravalle G, Grassi G. Obesity and hypertension. Pharmacol Res. 2017;122:1-7.

4. Aroor AR, DeMarco VG, Jia G, et al. The Role of Tissue ReninAngiotensin-Aldosterone System in the Development of Endothelial Dysfunction and Arterial Stiffness. Front Endocrinol (Lausanne). 2013;4:161.

5. Cavero-Redondo I, Tudor-Locke C, Álvarez-Bueno C, et al. Steps per Day and Arterial Stiffness: Systematic Review and Meta-Analysis. Hypertension. 2019;73(2):350-363.

6. Mancia G, De Backer G, Dominiczak A, et al. 2007 Guidelines for the Management of Arterial Hypertension: The Task Force for the Management of Arterial Hypertension of the European Society of Hypertension (ESH) and of the European Society of Cardiology (ESC). $J$ Hypertens. 2007;25(6):1105-1187.

7. Van Varik BJ, Vossen LM, Rennenberg RJ, et al. Arterial stiffness and decline of renal function in a primary care population. Hypertens Res. 2017;40(1):73-78.

8. AlGhatrif M, Strait JB, Morrell $\mathrm{CH}$, et al. Longitudinal trajectories of arterial stiffness and the role of blood pressure: The Baltimore longitudinal study of aging. Hypertension. 2013;62(5):934-941.

9. Labat C, Temmar M, Nagy E, et al. Inflammatory mediators in saliva associated with arterial stiffness and subclinical atherosclerosis. $J$ Hypertens. 2013;31(11):2251-2258.

10. Vlachopoulos C, Aznaouridis K, Stefanadis C. Prediction of Cardiovascular Events and All-Cause Mortality With Arterial Stiffness. A Systematic Review and Meta-Analysis. J Am Coll Cardiol. 2010;55(13):1318-1327.

11. Mitchell GF, Hwang SJ, Vasan RS, et al. Arterial stiffness and cardiovascular events: The framingham heart study. Circulation. 2010;121(4):505-511.

12. Benetos A, Adamopoulos C, Bureau JM, et al. Determinants of accelerated progression of arterial stiffness in normotensive subjects and in treated hypertensive subjects over a 6-year period. Circulation. 2002;105(10):1202-1207.

13. Meng L, Zhao D, Pan Y, et al. Validation of Omron HBP-1300 professional blood pressure monitor based on auscultation in children and adults. $B M C$ Cardiovasc Disord. 2016;16(1):1-5.

14. Takahashi H, Yokoi T, Yoshika M. Validation of three automatic devices for the self-measurement of blood pressure according to the European Society of Hypertension International Protocol revision 2010: the Omron HEM-7130, HEM-7320F, and HEM-7500F. Blood Press Monit. 2015 Apr;20(2):92-97.

15. http://www.pns.icict.fiocruz.br/arquivos/Novos/Manual-deAntropometria-pdf
16. Doupis J, Papanas N, Cohen A, et al. E Pulse Wave Analysis by Applanation Tonometry for the Measurement of Arterial Stiffness. Open Cardiovasc Med J. 2016;10(1):188-195.

17. Pires VP. Estudo Comparativo De Medição Da Velocidade Da Onda De Pulso: Vasocheck versus Complior. 2012;

18. Van Bortel LM, Laurent S, Boutouyrie P, et al. Expert consensus document on the measurement of aortic stiffness in daily practice using carotidfemoral pulse wave velocity. J Hypertens. 2012;30(3):445-448.

19. Passos VM de A, Assis TD, Barreto SM. Hypertension in Brazil: estimates from population-based prevalence studies. Epidemiology and Health Services. 2006;15(1).

20. Lessa Í, Magalhães L, Araújo MJ, et al. Arterial hypertension in the adult population of Salvador (BA) —Brazil. Arq Bras Cardiol. 2006;87(6):747_ 756.

21. Lobo LAC, Canuto R, Dias-da-Costa JS, et al. Temporal trend in the prevalence of systemic arterial hypertension in Brazil. Cad Saude Publica. 2017;33(6).

22. Nogueira D, Faerstein E, Coeli CM, et al. Reconhecimento, tratamento e controle da hipertensão arterial: Estudo Pró-Saúde, Brasil. Pan Am J Public Heal. 2010;27(2):103-109.

23. Cipullo JP, Vilela Martin JF, De Souza Ciorlia LA, et al. Hypertension prevalence and risk factors in a Brazilian urban population. Arq Bras Cardiol. 2010;94(4):519-526.

24. Neri MC, Soares WL. Estimating the impact of income on health through income transfer programs for poor elderly in Brazil. Cad Saude Publica. 2007;23(8):1845-1856.

25. Piccini RX, Victora CG. Systemic arterial hypertension in a urban area of southern Brazil: prevalence and risk factors. Rev Saude Publica. 1994;28(4):261-267.

26. Cunha PG, Cotter J, Oliveira P, et al. Pulse wave velocity distribution in a cohort study: Fromarterial stiffness to early vascular aging. J Hypertens. 2015;33(7):1438-1445.

27. Safar ME, Asmar R, Benetos A, et al. Interaction between hypertension and arterial stiffness an expert reappraisal. Hypertension. 2018;72(4):796805 .

28. Pereira T, Maldonado J, Pereira L, et al. Aortic stiffness is an independent predictor of stroke in hypertensive patients. Arq Bras Cardiol. 2013;100(5):437-443.

29. Pizzi O, Brandão AA, Eliane M, et al. Pulse wave speed - the method and its prognostic implications on arterial hypertension. Rev Bras Hipertens. 2006;13(1):59-62.

30. Laurent S, Katsahian S, Fassot C, et al. Aortic stiffness is an independent predictor of fatal stroke in essential hypertension. Stroke. 2003;34(5):1203-1206.

31. Avolio AP, Chen SG, Wang RP, et al. Effects of aging on changing arterial compliance and left ventricular load in a northern Chinese urban community. Circulation. 1983;68(1):50-58.

32. Farro I, Bia D, Zócalo Y, et al. Pulse wave velocity as marker of preclinical arterial disease: Reference levels in a Uruguayan population considering wave detection algorithms, path lengths, aging, and blood pressure. Int $J$ Hypertens. 2012;2012.

33. Alvim R de O, Santos PCJL, Bortolotto LA, et al. Arterial Stiffness: Pathophysiological and Genetic Aspects. Int $J$ Cardiovasc Sci. 2017;30(5):433-441.

34. Mikael L de R, de Paiva AMG, Gomes MM, et al. Vascular Aging and Arterial Stiffness. Arq Bras Cardiol. 2017;109(3):253-258.

35. Muhammad IF, Borné Y, Östling G, et al. Arterial stiffness and incidence of diabetes: A population-based cohort study. Diabetes Care. 2017;40(12):1739-1745. 